\title{
La ciencia ficción distópica ante el franquismo: otro frente de disidencia
}

\author{
Mikel PeREGRINa CASTAÑOS \\ Universidad Complutense de Madrid \\ peretorian@gmail.com
}

\begin{abstract}
RESUMEN
La ciencia ficción se desarrolló en España durante la etapa final del franquismo. Sus autores escribieron principalmente cuentos. La distopía fue el subgénero predominante en sus creaciones. A pesar del potencial crítico de la distopía, estos escritores no consiguieron configurar un proyecto sólido de disidencia. A sus textos se les suprimió su valor como literatura crítica por parte de los dos discursos dominantes en el momento, el oficial y el que representaba la novela social.
\end{abstract}

Palabras clave: Cuento, ciencia ficción española, distopía, franquismo.

\begin{abstract}
Science-fiction was developed in Spain at the end of Francoism. Chiefly, the authors used to write short-stories. The dystopia was the main subgenre practised in their creations. In spite of the dystopian critical potential, these writers did not manage to organise a strong project of disagreement. The value as critic literature from these texts was suppressed by the two dominant speeches, the official and the other represented by the social novel.
\end{abstract}

Keywords: Short-story, Spanish Science Fiction, Dystopia, Francoism.

Sumario: 1. Introducción, 2. Ciencia ficción y distopía, 3. Cuatro categorías, cuatro estados de madurez, 4. Conclusiones, 5. Corpus textual

\section{Introducción}

Al menos durante los años finales del franquismo ${ }^{1}$, se consideró que la ciencia ficción española, a diferencia de la anglosajona, se centraba más en la faceta humana. En ese sentido, la distopía, tan sociológica, constituye uno de los principales subgéneros tratados. En medio de este contexto histórico, y siguiendo la

\footnotetext{
${ }^{1}$ Para mayor exactitud, se hace referencia al periodo cronológico comprendido entre 1966, fecha de la publicación de la Primera antología española de ciencia ficción, y 1975, el año del fallecimiento del dictador.
} 
postura de Fernando Ángel Moreno y Daniel Ferreras, las visiones expresadas por la distopía no fueron del agrado de la dictadura, pues hablamos de una modalidad narrativa basada en el progreso científico, centrada en preocupaciones que conciernen a la humanidad en general y llena de representaciones peligrosas para cualquier régimen totalitario ${ }^{2}$.

En concreto, se trata de un corpus conformado por cerca de cuarenta cuentos, el cual no ha recibido prácticamente atención alguna por parte del mundo académico. Estos textos provienen principalmente de dos fuentes: 1) la revista de ciencia ficción y fantasía Nueva dimensión, que se publicó en España entre 1968 y 1983 y que alcanzó un total de 148 ejemplares; y 2) varias antologías promovidas por aficionados y publicadas por editoriales profesionales, cuyo objetivo era promover a los escritores españoles de ciencia ficción. Al observar el corpus se percibe que hay muchos autores, y de la inmensa mayoría sólo hay un cuento. Los únicos que poseen una obra algo más extensa son Luis Vigil, Domingo Santos y Juan G. Atienza. El desconocimiento que se mantiene sobre estos escritores responde a una realidad: la forma en que se desarrolló la ciencia ficción en España.

Cuando en 1949 don Ramón Menéndez Pidal escribe su ensayo Los españoles en la literatura, alegará como característica predominante de las letras hispanas el realismo, entendido como un afán por reflejar la realidad del autor dentro de las obras de ficción. De este modo, Menéndez Pidal señala que «una particularidad de este realismo se manifiesta en la escasez de elementos maravillosos» ${ }^{3}$. Con ello aplica un calificativo limitador con el que se margina una parte de la producción literaria. Su postura fue adoptada por el discurso político hegemónico del momento, especialmente por medio de los censores eclesiásticos, puesto que la fantasía, junto al humor, es una de las herramientas desvirtuadoras que llevan a la heterodoxia.

$\mathrm{Su}$ contraposición, es decir, la pretensión de crítica interna, ha sido vinculada a la novela social de los años cincuenta. Se considera que, al mostrar una realidad cruel y desalmada donde pierden los más desfavorecidos en beneficio de caciques o señores poderosos, los autores realizaban una crítica al discurso franquista dominante. Su intención, en palabras de Francisco Álamo Felices, era «despertar o iluminar la conciencia frente a las injusticias de la clase dominante burguesa en un estado dictatorial $»^{4}$. De esta forma, a partir del radicalismo de esta postura, los géneros no miméticos, es decir, aquéllos que no reflejaran la realidad empírica, la realidad compartida por el autor y el lector, eran calificados de arte escapista y evasivo. Se trató de una visión simplista y empobrecedora que negaba el poder crítico de la fantasía.

\footnotetext{
${ }^{2}$ D. Ferreras y F. A. Moreno (2012), pp. 41 y ss.

${ }^{3}$ R. Menéndez Pidal (1971), p. 94.

${ }^{4}$ F. Álamo Felices (1996), p. 205.
} 
Por suerte, Ana Casas y David Roas, en el «prólogo» a La realidad oculta, trazaron una «contrahistoria» ${ }^{5}$ de lo fantástico en la literatura española del siglo XX. Con ella, Casas y Roas demostraron que si «se rastrea en la producción de los narradores españoles, no sólo se hace evidente que las obras fantásticas son muchas y de calidad, sino también que éstas aparecen en momentos en los que la presión realista es enorme» ${ }^{6}$. El presente artículo continúa en esta dirección, pero desde un aspecto más concreto.

En España lo que encontraría la ciencia ficción en sus inicios fue una aversión que la legaría a un gueto donde los aficionados, para remarcar la diferencia, optaron por discriminar desde su marginación a la corriente general de la literatura, que llamaban mainstream. Como consecuencia, los aficionados se aíslan de la cultura oficial y se constituyen como grupo autónomo. En estas circunstancias de aislamiento, el género se desarrolla en España mediante una pobreza de medios que imposibilitó que los escritores que acudían a ella pudieran alcanzar un nivel profesional con sus creaciones. Por ello, como correctamente argumentó Florence Behm, en España raro era el escritor de ciencia ficción al que se le remuneraba algo por el texto publicado?

Ante esta realidad, las posibilidades de publicación se limitaban o a la revista Nueva dimensión o a las antologías que pretendieron promocionar esta incipiente escuela española de ciencia ficción. Los escritores optaron principalmente por practicar el cuento, material más fácil de incluir en esos tipos de publicaciones. No obstante, conviene puntualizar aquí que la historia de la ciencia ficción demuestra lo fructífera que ha sido la relación entre este género y la modalidad narrativa breve. A parte de su vinculación histórica, está su vinculación formal.

\section{La ciencia ficción y la distopía}

Para definir la ciencia ficción, conviene partir de la noción de Darko Suvin. En su libro Metamorfosis de la ciencia ficción, la definió como la literatura del «extrañamiento cognitivo» ${ }^{8}$. El primero de ambos términos, el extrañamiento, se refiere a que los mundos ficcionales que aparecen en la obras fictocientíficas no reflejan nuestro mundo. Para conseguir este efecto, el escritor debe alejarse de la realidad empírica para crear un universo ficcional nuevo. Sin embargo, la cognición supone una paradoja con el primer término, puesto que ese ejercicio imaginativo queda constreñido a un inviolable cumplimiento de las leyes naturales que rigen

5 Se toma el término del teórico de la historia de la literatura M. J. Valdés San Martín (2005), p. 128

${ }^{6}$ D. Roas y A. Casas (2008), p. 10.

${ }^{7}$ F. Behm (2003), p. 53.

${ }^{8}$ D. Suvin (1984), p. 26. 
nuestro universo. El mundo ficcional debe mantener la ilusión de ser un mundo verificable, plausible al lector.

Cognición también hace referencia al modo de trabajo de los autores del género. Se trata de un método científico en el que el escritor establece una hipótesis, una premisa especulativa, a partir de un elemento que toma de su tiempo, después lo desarrolla hiperbolizado en la obra y así obtiene unas conclusiones. A ese elemento del que parte para construir el universo ficcional Suvin lo denominó novum o innovación cognoscitiva. El novum hace de mediador entre lo literario y lo extraliterario, entre lo ficticio y lo empírico. En el caso del cuento, se viene a caracterizar por incluir un sólo novum. El uso de una de estas premisas especulativas - aclara Itsvan Csicsery-Ronay - posibilita una economía estética e intelectual en la que desarrollar esa única idea para obtener conclusiones reveladoras mediante el control de las condiciones del experimento ficcional ${ }^{9}$.

Dentro de esta definición propuesta por Suvin, la distopía se amolda muy bien al planteamiento del novum como generador de la trama gracias a las herramientas del extrañamiento cognitivo. Lyman Tower Sargent, cuando discierne entre los modelos de la utopía, señaló que la distopía, en concreto, se caracteriza por representar una sociedad inexistente que el escritor describe al lector con sumo detalle y que resulta peor que la sociedad en la que ambos viven ${ }^{10}$. En ese sentido, como puntualizó Juan Ignacio Ferreras, su visión del provenir puede volverse catastrofista, es decir, en ella las contradicciones de la sociedad presente no solamente no encuentran solución en el futuro, sino que, al acentuarse, producen la catástrofe de toda la humanidad ${ }^{11}$.

Su poder crítico reside en su estrategia narrativa. A diferencia de las utopías, que comenzaban con el desplazamiento temporal, en estas obras el lector se ve inmerso en el mundo extrañado desde la primera página. La trama tiende a desarrollarse sobre un individuo común inserto en esa sociedad negativa, que empieza con reconocer su condición de alienado, por lo que se traza una relación entre su experiencia individual y el funcionamiento de todo el sistema. La oposición llega por dos medios: el lenguaje y la memoria. En estas obras el lenguaje es una herramienta de poder y dominación por parte de las estructuras hegemónicas. El descubrimiento del lenguaje oculto por el protagonista le conduce a la disidencia. Es la recuperación de un mundo anterior y perdido, un proceso que se realiza mediante la memoria.

En muchas ocasiones el despertar de la conciencia llega a través del amor. Gracias a este nuevo contacto y actitud vital, el singular inadaptado encuentra aliados que le enseñan la verdad del sistema y le introducen en el círculo de

${ }^{9}$ I. Csicsery-Ronay Jr. (2008), p. 67.

${ }^{10}$ L. T. Sargent (1994), p. 9.

${ }^{11}$ J. I. Ferreras (1972), p. 120. 
oposición ${ }^{12}$. A partir de ese punto Tom Moylan considera dos posibles finales que hacen que la distopía se sitúe a media distancia entre la utopía y la antiutopía. Si la historia deriva en la huida del protagonista del sistema, su término es positivo, pues ofrece una salida, y entonces tiende a la utopía. Si, por contra, el sistema vence y termina con la disidencia del individuo, aplastándolo, el final es negativo y tiende a la antiutopía ${ }^{13}$. Esta última vertiente supone una visión pesimista, que es la que predomina en este corpus.

Para percibir de forma más clara los rasgos de la distopía, el relato de Luis Vigil, «Cuando sólo resta la muerte», constituye un buen ejemplo. Vigil, uno de los tres fundadores de la revista Nueva dimensión, escribió varios cuentos que se circunscriben a este subgénero fictocientífico, como «Notas del juicio de un elemento subversivo». Sin embargo, es más interesante «Cuando sólo resta la muerte». Aquí el texto es tan esquemático que los personajes no tienen nombre, sino que adquieren un carácter alegórico.

La historia recuerda a la sala de tortura 101 en la novela de Orwell, $1984^{14}$. E1 protagonista, llamado Hombre Solo, es un individuo sometido a una tortura física y psicológica para ser resocializado, reinsertado en el Estado. El torturador es la Policía Ideológica, artífice de la reconversión. En la tortura se reflexiona, en especial, sobre la relación entre individuo y masa. El personaje defiende su individualidad, se vuelve en contra de la masa gracias al conocimiento, pues trabaja en el fondo de documentación de una biblioteca (tiene acceso a conocimiento del pasado). Por ello, considera que el Estado ha creado al hombre masa, ha deshumanizado al ser humano.

En las sesiones se desarrolla la historia en sucesivas analepsis, las cuales se diferencian tipográficamente mediante la cursiva. Aparece así el personaje femenino que propulsa al protagonista a enfrentarse al sistema. Pero es una historia de amor frustrado, pues Ella acaba reintegrándose en el sistema. Al Hombre Solo únicamente le queda sucumbir. Al terminar el proceso de reconversión, pasa a llamarse el Hombre Que Ya No Estaba Solo. Sin embargo, en este panorama pesimista, el narrador se permite un sarcasmo final cuando el Estado autoriza al protagonista a morir: «Pero, en el fin, el Hombre se enfrentó de nuevo, Solo, con la Nada» ${ }^{15}$.

De este modo, a la hora de leer estas obras, el lector entra en un juego donde debe discernir entre la yuxtaposición de elementos del mundo empírico con otros ajenos a éste, generados mediante el extrañamiento narrativo. Por un lado, el novum provoca un alejamiento de la realidad empírica; por otro, hay una lectura realista de

\footnotetext{
12 T. Moylan (2000), pp. 148-150.

${ }^{13}$ T. Moylan (2000), p. 147.

${ }^{14}$ Se sigue para esta referencia Orwell (2012) por considerarla edición crítica.

${ }^{15}$ L. Vigil (1970), p. 34.
} 
esa realidad ficcional. Es el proceso inverso, el cual la mexicana Noemí Novell calificó como la familiarización de lo extraño ${ }^{16}$. Como consecuencia, según explica el teórico Fernando Ángel Moreno, se generan movimientos continuos de tensión y distensión entre nuestra realidad empírica y el mundo representado, es decir, entre lo familiar y el extrañamiento ${ }^{17}$. Suvin denominó a esos movimientos «feedback oscillation», un fluctuante ir y venir ${ }^{18}$.

Para conseguir este efecto, el autor desglosa el mundo ficcional y lo va ofreciendo disperso en la trama mediante fragmentos de información. El lector necesita ir identificando esas piezas de información para construir todo el mundo ficcional y entender la actuación de los personajes en relación a los parámetros del mundo en el que se insertan. Para ello, el lector debe crear paradigmas semánticamente coherentes y analíticos del mundo ficcional a partir de la información dada. El truco está en que según madura la distopía, estos paradigmas quedan cada vez más aludidos y no se explicitan en el discurso, por lo que el lector adquiere un papel más activo en la reinterpretación del mundo ficcional.

\section{Cuatro categorías, cuatro estadios de madurez}

Por ese motivo, a la hora de exponer este corpus textual, se han establecido cuatro categorías, en las que se observará una progresiva complejidad literaria, especialmente en el discurso, sobre el esquema explicado. En el primer grupo se encuentran la mayoría de los escritores que poseen un solo cuento, por lo que funciona como cajón de sastre. Normalmente son distopías más clásicas. No suelen incluir todos los elementos del esquema, ni juegan con el discurso narrativo. Muchos siguen valiéndose de elementos decimonónicos, como la sustitución del desplazamiento espacial por uno temporal, por ejemplo, en «Condena a una vida sin sentido», de José Azperena. En otras ocasiones optan por un modelo expositivo para describir esa sociedad futura negativa, en detrimento de la trama, como hace José J. Sánchez Martínez en «Historia de Xelik: El ciudadano HY-3O47P5». Lo mismo sucede con Luis García Lecha en «¿Dónde hay espacio?», quien mayormente sólo dibuja un mundo futuro angustioso donde lleva el problema de la superpoblación a su último exponente.

A pesar de la afirmación realizada sobre el pesimismo de las distopías, hay alguna que otra excepción con final positivo. Un caso es «Como en el siglo I», de Luis González Santos. Aquí un matrimonio que espera un niño huye a causa de la prohibición en ese mundo de la procreación natural con el fin de controlar el nivel de la población. Rechazan las comodidades de la civilización para unirse con los resistentes. De esta forma, se critica que el progreso tecnológico coarta nuestra

\footnotetext{
${ }^{16}$ N. Novell (2008), p. 211

${ }^{17}$ F. A. Moreno (2010), p. 183.

${ }^{18}$ T. Moylan (2000), p. 8.
} 
libertad. Por otro lado, el cierre positivo tiene más que ver con el final feliz propio de la literatura popular que con un ideario de esperanza utópica, del que se hablará más adelante. No obstante, dentro de todo este extenso grupo, hay textos que sobresalen, como «La pareja que amaba la soledad», de Alfonso Álvarez Villar, o «La máquina que escribió un "best-seller"», de Pedro Sánchez Paredes.

Por otro lado, uno de los autores de obra más dilatada fue Domingo Santos, quien conforma una segunda categoría. A pesar de no diferenciarse en exceso a los escritores de la categoría precedente, tiene mayor pericia literaria, sus mundos ficcionales están más desarrollados y sus nova son más concretos. En realidad llamado Pedro Domingo Mutiñó, es considerado hoy en día entre los aficionados como principal impulsor de la ciencia ficción española. Al destacar más por su labor editorial, Santos practicó el cuento en estos años, género en el que para Florence Behm ha cosechado sus mayores éxitos literarios ${ }^{19}$. Varios de esos relatos los reunió en 1981 , en Futuro imperfecto ${ }^{20}$.

En este libro hay dos grandes preocupaciones: la ecología y el poder económico. La primera es patente en cuentos como «Smog», sobre la polución urbana, y la segunda en «Negocios del corazón», sobre la venta de órganos. Ambas preocupaciones aparecen unidas, por ejemplo, en «Encima de las nubes», una crítica sobre los comportamientos empresariales inmorales sin atender a repercusiones medioambientales ocasionadas por su actividad. Aun así, resulta más ilustrativo destacar «Una fábula», un relato que había aparecido previamente en el número 9 de Nueva dimensión con el título «Un lugar llamado Tierra». En esta ocasión el autor opta aparentemente por la utopía, aunque según se avanza en la lectura se percibe que dicha sociedad no es tan perfecta como inicialmente se piensa. Citando a Yolanda Molina-Gavilán:

Esta nueva sociedad condena a sus habitantes al trabajo alienante y absurdo de un futuro comunista basado en el pragmatismo consumista. Los problemas mundiales que provocan su aparición son tres tendencias de la sociedad presente que Santos exagera: la superpoblación, la progresiva automatización y la ineficacia de los organismos rectores para responder a tales problemas. La ideología a la que responde este relato es fundamentalmente antiprogresista por su presentación de un mundo rural idílico y un mundo urbano despersonalizador y aplastante . $^{21}$.

A través del protagonista, el último hombre inadaptado, símbolo anacrónico de un pasado olvidado, se destacan las renuncias que se han realizado para alcanzar la estabilidad y el bienestar: el ser humano queda reducido a un nivel de autómata. El

\footnotetext{
${ }^{19}$ F. Behm (2003), p. 84.

${ }^{20}$ Ver Santos (1981).

${ }^{21}$ Y. Molina-Gavilán (2002), p. 158.
} 
final resulta esperable, el individuo marginal termina por ser integrado a esa sociedad futura. Cualquier tipo de disidencia muere con él. En ese nivel señaló Juan Ignacio Ferreras que el fracaso de un individuo es insignificante pues en realidad comprende el fracaso de toda la humanidad ${ }^{22}$.

En la tercera categoría, los escritores empiezan a jugar con las posibilidades de la narrativa, huyendo de modelos lineales. Un ejemplo sería «El escaparate», del guionista Juan Tébar. Aun así, sobresale en este estadio Juan García Atienza. A pesar de que durante una década escribió obras fantásticas y de ciencia ficción, hoy en día es recordado por sus libros sobre leyendas hispánicas, hasta el punto de haber sido considerado una autoridad en la España secreta, esotérica y mágica. Dentro de la distopía, destacan tres cuentos suyos: «Limpio, sano y justiciero», «Las tablas de la ley» $\mathrm{y}$ «El pisito solariego».

El más interesante es el segundo de ellos, «Las tablas de la ley», donde Atienza aborda el tema de la eugenesia. Desarrolla un futuro distópico cuyo gobierno mundial clasifica a los humanos por grupos genéticos e imposibilita legalmente la reproducción de miembros de distinto grupo. El protagonista, Fernando Silva, pertenece a un grupo minoritario, K, formado por 8964 hombres y tan sólo 36 mujeres. En este sentido, su mayor obsesión es buscar a esas ansiadas mujeres para entablar una relación amorosa. Finalmente encontrará a la ideal, Virginia, aunque desgraciadamente ella está casada. Fernando Silva recurrirá a unos abogados que se encargarán de asesinar al marido y conseguir los trámites legales para que pueda suplantarlo. En medio de la felicidad, tras despedirse de Virginia, ahora su mujer, para marcharse a trabajar, sorprende desde el aire a un nuevo pretendiente de Virginia.

Su primera innovación es el final abierto, donde se ofrece la suposición de una historia que se repite, pues da a entender que el nuevo pretendiente, otro desesperado miembro del grupo $\mathrm{K}$, recurrirá a la misma artimaña que Fernando Silva o a otra similar para conseguir a Virginia. Pero el relato también jugará a nivel discursivo. Dentro de él hay numerosos textos en cursiva que explican ese mundo ficcional. Esos textos forman parte del mundo ficcional, pues son citas de leyes, anuncios publicitarios o estudios estadísticos, lo que confiere mayor verosimilitud a la distopía.

También hay que destacar el último de los tres relatos, «El pisito solariego», donde todo el discurso constituye una carta de reclamación, una apelación del protagonista para que se le retire una multa. A través de los argumentos de la reclamación el lector va reconstruyendo el mundo ficcional: una sociedad dominada por un estado totalitario de corte socialista, donde las posesiones son escasas, pero las necesidades primarias han sido resueltas. El mundo ficcional queda aludido. El lector debe otorgarle sentido a partir de la localización de los fragmentos de

22 J. I. Ferreras (1972), p. 127. 
información más arriba explicados, por lo que adquiere una postura activa. Otro ejemplo con modelo epistolar es «En un mundo feliz», de Ana María Botella, aunque menos logrado.

Finalmente, en la cuarta y última categoría, sobresalen dos cuentos que ya se caracterizan por proponer un modelo experimental con el lenguaje: «Oasis», de Carlos Reñé y «En el alba de la quinta oscuridad», de Fernando P. Fuenteamor. Ambos autores estuvieron vinculados al fanzine Zikkurath y promovieron el movimiento literario que se denominó «Nova-Expression». Se trató de un grupo de escritores jóvenes que se identificaban con la Nueva Ola anglosajona y que, situados fuera de cualquier canal oficial, conectaban con movimientos contraculturales $^{23}$. Al igual que los escritores de la Nueva Ola, defendieron un afán experimentador en el discurso, pues buscaban una remodelación formal del género $^{24}$.

De ambos relatos, resulta más innovador el de Reñé: «Oasis». Se trata de una oscura distopía donde el protagonista, Águilas, encuentra en el suicidio la única salida a la pesadilla de sociedad en la que vive. Se trata de un mundo cruel y desalmado, completamente anárquico, donde la vida de un individuo no tiene valor y todo son trabas para el desarrollo del día a día. Para la plasmación de este mundo ficcional se recrea una acción habitual y rutinaria: la asistencia al puesto laboral. La herramienta del extrañamiento aparece en medio de la cotidianidad. La escena que hunde definitivamente a Águilas en la depresión es la indiferencia ante la muerte de un individuo:

Finalmente es arrojado al vacío [...]. Una ola de metal se abalanza sobre él y el hombre rebota una y otra vez hasta fragmentarse en pequeños trozos anónimos. Ni siquiera ha llegado a tocar el suelo. Es imposible detenerse. Águilas contempla esto con los ojos muy abiertos. ¿Cómo es posible? Una mancha roja en el parabrisas. ¡Bah! Es uno que han tirado desde arriba esos bastardos; suelen hacerlo, ;olvídalo! ${ }^{25}$.

Formalmente plantea la innovación en el fragmento onírico inicial, una pesadilla de hundimiento en el abismo personal del protagonista, que funciona como prolepsis: «Caes por la espiral infinita de color arco iris y tu piel se quema con los recuerdos. Caes, sintiéndote felizmente arrastrado hacia un caleidoscopio de momentos todavía vivos» ${ }^{26}$. Estilísticamente juega con enunciados muy cortos. Usa el presente de indicativo, que confiere sensación de instantaneidad y acerca ese futuro al tiempo del lector. Se prescinde casi absolutamente de la descripción; las

${ }^{23}$ C. Saiz Cidoncha (1988), pp. 421-424.

${ }^{24}$ H. Merrick (2009), p. 102.

${ }^{25}$ C. Reñé (1974), p. 67.

${ }^{26}$ C. Reñé (1974), p. 63. 
explicaciones del mundo ficcional se reducen al mínimo, incrementando el papel activo del lector.

\section{Conclusiones}

Tras la exposición realizada, queda claro que la ciencia ficción española durante el franquismo fue considerada como una manifestación de literatura popular. No obstante, podría haber sido una tercera vía alternativa a la clásica visión de «las dos Españas», estudiada, entre otros, por el historiador Santos Julián ${ }^{27}$. Esa faceta disidente se prefigura a través del predominio de la distopía. Desde luego, como defiende Tom Moylan, toda narrativa distópica entabla un encuentro estético y epistemológico con su coyuntura histórica. El propio acto de escritura en estas distopías es un acto de resistencia. En la distopía, como en la ciencia ficción, para analizar el presente, hay que distanciarse de él y adquirir perspectiva, ponerlo en comparación con algo diferente ${ }^{28}$.

$\mathrm{Su}$ práctica ficcional tiene el potencial de revisar el mundo en formas que provocan, además de placer, respuestas subversivas en los lectores, puesto que recrea el presente empírico y lleva a los lectores a un espacio-tiempo alternativo. Se la puede concebir como una literatura didáctica, puesto que, al crear sociedades a partir del mundo empírico, lleva a pensar sobre lo que existe y no existe en nuestra sociedad. Es mediante este recurso, los dos parámetros de Suvin del extrañamiento y la cognición, como en la naturaleza de la distopía se percibe su finalidad subversiva.

Dentro del corpus aquí reunido, hay un elemento patente en la mayoría de los cuentos que ya percibió en su tesis de la historia de la ciencia ficción española Carlos Saiz Cidoncha: el pesimismo de sus autores, centrados en plasmar sociedades alienantes y deshumanizadas donde el individuo es vencido, acabando con su disidencia ${ }^{29}$. Estos finales pesimistas hacen que los autores cierren el horizonte esperanzador que conduciría a esa representación negativa del futuro hacia un modelo utópico. La búsqueda de la libertad del individuo queda anulada por el sistema. No hay posibilidad de huida. Este pesimismo claramente se puede relacionar con el momento histórico de España. En medio del control de la dictadura y de la censura, en un tiempo donde dominaba el gris, se anula el horizonte de esperanza. Es imposible que surgiese un proyecto social utópico, ese deseo llamado utopía del que hablaba Fredric Jameson ${ }^{30}$.

Esta postura se sostiene a través del cambio que se va apreciando tras la muerte del dictador, donde las distopías aluden de forma más caricaturesca al sistema

${ }^{27}$ S. Juliá (2004), pp. 409-445.

${ }^{28}$ T. Moylan (2000), p. 28.

${ }^{29}$ C. Saiz Cidoncha (1988), p. 343

${ }^{30}$ F. Jameson (2009), pp. 335-351. 
dictatorial español, como hace Carlos Saiz Cidoncha en «Libertad de palabra» o Francisco Taibo II en «Llamaradas para fechas vacías»" ${ }^{31}$. Con la transición se construye temporalmente un proyecto utópico que confiere a la distopía la búsqueda de salidas a sistemas alienantes, que se percibe en «¿Qué me das a cambio?», de Juan Carlos Planells ${ }^{32}$. Aquí se explora un futuro en el que se retorna a una economía de trueque. A diferencia de los relatos explicados, el protagonista sobrevive, se adapta a la nueva situación, por lo que se percibe el horizonte de esperanza que se conectaría con el nuevo pensamiento utópico de la transición española. Por ese motivo, la distopía en el franquismo no llegó a ser un proyecto sólido de disidencia. Relegado y suprimido su valor como literatura crítica por parte de los dos discursos dominantes en el momento, se convirtió en una disidencia resignada.

\section{Corpus textual}

ÁlVAREZ VILLAR, Alfonso: «La pareja que amaba la soledad», en José A. Llorens Borrás (comp.), Antología de novelas de anticipación, Barcelona, Acervo, 1967, vol. VII, pp. 95-101.

ARroyo GARCÍA, Juan: «El planeta de Sigrid Mortensen», en Narraciones españolas de ciencia ficción, Barcelona, Marte, 1974, pp. 169-174.

AZPERENA, José: «Condena a una vida sin sentido (¿Sobrevivir a toda costa?)», en Narraciones españolas de ciencia ficción, Barcelona, Marte, 1974, pp. 155-160.

BENAVENTE FERNÁNDEZ, Doroteo: «Medio siglo después», en Narraciones españolas de ciencia ficción, Barcelona, Marte, 1974, pp. 25-32.

BAS BERNABEU, Abdon: «Trampa a la inmortalidad», en Narraciones españolas de ciencia ficción, Barcelona, Marte, 1974, pp. 223-227.

Botella, Ana María: «Un mundo feliz», en Narraciones españolas de ciencia ficción, Barcelona, Marte, 1974, pp. 195-201.

CARMONA, Ángel: «Historia de un parkicidio», Nueva dimensión, 42 (1973), pp. 22-25.

CRESPO, José Ángel: «31 de diciembre de 5027», Nueva dimensión, 5 (1968), pp. 25-30.

EXtremadura, Juan: «Vivir deportivamente», en Carlos Buiza (ed.), Antología social de la ciencia-ficción, Algorta, Zero ZYX, 1972, pp. 55-58.

GARCÍA ATIENZA, Juan: «Limpio, sano y justiciero», Anticipación, 1 (1966), pp. 6068.

: «Las tablas de la ley», en José A. Llorens Borrás (comp.), Antología de novelas de anticipación, Barcelona, Acervo, 1967, vol. VII, pp. 301-322.

\footnotetext{
${ }^{31}$ Ver Taibo (1978).

${ }^{32}$ Ver Planells (1982).
} 
: «Servicio de puerta a puerta», en José A. Llorens Borrás (comp.), Antología de novelas de anticipación, Barcelona, Acervo, 1969, vol. IX, pp. 31-38.

: «El pisito solariego», en Raúl Torres (ed.), Antología española de ciencia ficción, Madrid, PPC, 1972, vol. I, pp. 57-61.

GARCÍA LECHA, Luis: «¿Dónde hay espacio?», en José A. Llorens Borrás (comp.), Antología de novelas de anticipación, Barcelona, Acervo, 1969, vol. IX, pp. 227-234.

GonZÁLEZ SANTOS, Luis: «Como en el siglo I», en José Antonio Salcedo (ed.), Antología de la ciencia ficción en lengua castellana, Madrid, Miguel Castellote, 1973, vol. II, pp. 155-172.

LEZCANO LEZCANO, Francisco: «Los intermedios», en José A. Llorens Borrás (comp.), Antología de novelas de anticipación, Barcelona, Acervo, 1967, vol. VII, pp. 35-42.

MARTíN SÁNCHEZ, José L.: «Aleutar, el último romántico», en José Antonio Salcedo (ed.), Antología de la ciencia ficción en lengua castellana, Madrid, Miguel Castellote, 1973, vol. II, pp. 265-280.

PÉREZ FUENTEAMOR, Fernando: «En el alba de la quinta oscuridad», Nueva dimensión, 56 (1974), pp. 68-70.

REÑÉ, Carlos: «Oasis», Nueva dimensión, 56 (1974), pp. 63-67.

RIBERA MONTAÑÁ, Jaime: «El vuelo de Ralph», en Narraciones españolas de ciencia ficción, Barcelona, Marte, 1974, pp. 141-146.

RODRÍGUEZ ELVIRA, J. J.: «SF 2500», Nueva dimensión, 44 (1973), pp. 46-51.

RODRíGUEZ MENTÓN, Ángel: «Tom y las moscas», Nueva dimensión, 59 (1974), pp. 76-77.

RUIZ GISPERT, Francisco: «El empleo», Nueva dimensión, 25 (1971), pp. 35-41.

SÁNCHEZ MARTínEZ, José J.: «Historia de Xelik: El ciudadano HY-3O47P5», en Narraciones españolas de ciencia ficción, Barcelona, Marte, 1974, pp. 233-238.

SÁNCHEZ PAREDES, Pedro: «La máquina que escribió un "best-seller"», en Raúl Torres (ed.), Antología Española de Ciencia Ficción, Madrid, PPC, 1972, vol. II, pp. 171-176.

SANTOS, Domingo: «... Si mañana hemos de morir», Nueva dimensión, 7 (1969), pp. $87-100$.

: «Un lugar llamado Tierra», Nueva dimensión, 11 (1969), pp. 100-137.

: «Negocios del corazón», Nueva dimensión, número extra 2 (1970), pp. 55-62.

: «El programa», Nueva dimensión, número extra 2 (1970), pp. 145-166.

: «Encima de las nubes», Nueva dimensión, 48 (1973), pp. 84-106.

: «Smog», en José Antonio Salcedo (ed.), Antología de la ciencia ficción en

lengua castellana, Madrid, Miguel Castellote, 1973, vol II, pp. 47-60.

TÉBAR, Juan: «El escaparate», Anticipación, 7 (1967), pp. 136-139.

VIGIL, Luis: «El ruido», Anticipación, 3 (1967), pp. 27-31.

: «Cuando sólo resta la muerte», Nueva dimensión, 14 (1970), pp. 28-34. 
: «Notas del juicio de un elemento subversivo», en Carlos Buiza (ed.), Antología social de la ciencia-ficción, Algorta, ZYX, 1972, pp. 25-30.

: «La muerte del Gran-ecólogo-al-que-no-habían-hecho-caso», Nueva dimensión, 51 (1973), pp. 107-109.

\section{OBRAS CITADAS}

ÁlAMO FELICES, Francisco: La novela social española. Conformación ideológica, teoría y crítica, Almería, Servicio de publicaciones de la Universidad de Almería, 1996.

BEHM, Florence: La ciencia ficción en España, s. 1., Asociación Española de Fantasía, Ciencia Ficción y Terror (AEFCFT), 2003.

CSICESRY-RonaY Jr., Itsvan: The Seven Beauties of Science Fiction, Middletown (Connecticut), Wesleyan University Press, 2008.

FERRERAS, Juan Ignacio: La novela de ciencia ficción. Interpretación de una novela marginal, Madrid, Siglo XXI, 1972.

Ferreras SaVoye, Daniel, y Moreno, Fernando Ángel: «Spanish Science Fiction and its Ghosts», Popular Culture Review, 2.23 (2012), pp. 41-48.

JAMESON, Fredric: Arqueologías del futuro. El deseo llamado utopía y otras aproximaciones de ciencia ficción, Madrid, Akal, 2009.

JuLIÁ, Santos: Historia de las dos Españas, Madrid, Taurus, 2004.

MENÉNDEZ PIDAL, Ramón: Los españoles en la literatura, Madrid, Espasa-Calpe, 1971.

MERRICK, Helen: «Fiction, 1964-1979», en Mark Bould et alii (ed.), The Routledge Companion to Science Fiction, New York, Routledge, 2009, pp. 102-111.

Molina-GAVILÁN, Yolanda: Ciencia ficción en español: una mitología moderna ante el cambio, New York, The Edwin Meller Press, 2002.

Moreno, Fernando Ángel: Teoría de Literatura de ciencia ficción. Poética y retórica de lo prospectivo, Vitoria, Portal Editions, 2010.

MoYlan, Tom: Scraps of the Untainted Sky. Science Fiction, Utopia, Dystopia. Boulder (Colorado), Westview Press, 2000.

Novell, Noemi: Literatura y cine de ciencia ficción. Perspectivas teóricas, Tesis doctoral dirigida por la Dra. Meri Torras Francés, Universitat Autònoma de Barcelona, Facultad de Letras, 2008.

ORWELL, George: 1984, Madrid, Destino, 2012.

PLANELlS, Juan Carlos: «¿Qué me das a cambio?», Nueva Dimensión, 140 (1982), pp. 21-37.

REÑÉ, Carlos: «Oasis», Nueva dimensión, 56 (1974), pp. 63-67.

ROAS, David, y CASAS, Ana: «Prólogo», en David Roas y Ana Casas (ed.), La realidad oculta: cuentos fantásticos españoles del siglo XX, Palencia, Editorial Menoscuarto, 2008, pp. 9-54. 
SAIZ Cidoncha, Carlos: «Libertad de palabra», Nueva Dimensión, 86 (1977), pp. 27-35.

SAIZ Cidoncha, Carlos: La Ciencia ficción como fenómeno de comunicación y de cultura de masas en España, Tesis doctoral dirigida por el Dr. Luis Núñez Ladeveze, Universidad Complutense de Madrid, Facultad de Ciencias de la Información, 1988.

SANTOS, Domingo: Futuro imperfecto, Barcelona, Edhasa, 1981.

SARGENT, Lyman Tower: «The Three Faces of Utopianism Revisited», Utopian Studies, vol. 5, no 1 (1994), pp. 1-37.

Suvin, Darko: Metamofosis de la ciencia ficción. Sobre la poética y la historia de un género literario, México D. F., Fondo de Cultura Económica, 1984.

TAIBO, Francisco Ignacio, II: «Llamaradas para fechas vacías», Nueva dimensión, $\mathrm{n}^{\circ} 105$ (1978), pp. 44-61.

VALDÉS SAN MARTÍN, Mario J.: «Historia de las culturas literarias: alternativa a la historia literaria», en Luis Beltrán Almería y José Antonio Escrig (ed.), Teorías de la historia literaria, Madrid, Arco/Libros, 2005, pp. 123-218.

VIGIL, Luis: «Cuando sólo resta la muerte», Nueva dimensión, 14 (1970), pp. 28-34. 